IZA DP No. 5797

External Monetary Shocks and Monetary Integration: Evidence from the Bulgarian Currency Board

Alexandru Minea

Christophe Rault

June 2011 


\title{
External Monetary Shocks and Monetary Integration: Evidence from the Bulgarian Currency Board
}

\author{
Alexandru Minea \\ CERDI, University of Auvergne \\ Christophe Rault \\ LEO, University of Orléans, \\ CNRS and IZA
Discussion Paper No. 5797
June 2011 \\ IZA \\ P.O. Box 7240 \\ 53072 Bonn \\ Germany \\ Phone: +49-228-3894-0 \\ Fax: +49-228-3894-180 \\ E-mail: iza@iza.org
}

Any opinions expressed here are those of the author(s) and not those of IZA. Research published in this series may include views on policy, but the institute itself takes no institutional policy positions.

The Institute for the Study of Labor (IZA) in Bonn is a local and virtual international research center and a place of communication between science, politics and business. IZA is an independent nonprofit organization supported by Deutsche Post Foundation. The center is associated with the University of Bonn and offers a stimulating research environment through its international network, workshops and conferences, data service, project support, research visits and doctoral program. IZA engages in (i) original and internationally competitive research in all fields of labor economics, (ii) development of policy concepts, and (iii) dissemination of research results and concepts to the interested public.

IZA Discussion Papers often represent preliminary work and are circulated to encourage discussion. Citation of such a paper should account for its provisional character. A revised version may be available directly from the author. 


\section{ABSTRACT \\ External Monetary Shocks and Monetary Integration: Evidence from the Bulgarian Currency Board ${ }^{*}$}

Starting July the 1st 1997, Bulgaria adopted a Currency Board (CB) monetary system. This paper aims at investigating if the adoption of the $C B$ monetary system, which involves the cost of loosing monetary autonomy, has provided a relatively better (with respect to other CEEC) monetary integration of Bulgaria with the European Monetary Union (EMU). Since Bulgarian monetary variables are endogenous under a $C B$, we focus on the ECB and FED interest rates as the main sources on monetary volatility. First, we find that ECB shocks are more rapidly absorbed and have less significant impact of domestic variables, with respect to other external monetary shocks (FED rate changes). Second, the responses of Bulgarian variables following changes in the ECB interest rate present lower persistence and significance, with respect to what the previous literature emphasized for other CEEC with monetary autonomy. This latter result still holds when accounting for different sources of cross-country heterogeneity outlined in the literature, thus supporting that the adoption of the $\mathrm{CB}$ may have worked as a rather good device in terms of integration of Bulgaria into the EMU.

JEL Classification: E42, E52

Keywords: currency board, Bulgaria, monetary shocks, ECB interest rate, FED interest rate

Corresponding author:

Christophe Rault

CNRS UMR 6221

University of Orleans

Rue de Blois-B.P.6739

45067 Orléans Cedex 2

France

E-mail: christophe.rault@univ-orleans.fr

\footnotetext{
" We would like to thank Stephen George Hall and two anonymous referees, as well as the participants to the CICM 2009 Conference (London) for very helpful comments on a previous version. Usual disclaimer applies.
} 


\section{Introduction}

The evolution of the Bulgarian economy between the fall of the communist wall and 1996 may be characterized by high instability. With only $20 \%$ of assets being privatized before 1997 and political pressure on banks to subsidy loss-generating state-owned companies, the financial system became increasingly fragile and accumulated massive amounts of "bad" credits. This "bad" dynamic in the transition process was accompanied by deterioration in monetary conditions. To overcome the reduction of foreign currency reserves to some 500 million USD, the monetary authorities proceeded to subsequent exchange rate devaluations in 1994-1995. These devaluations had only some temporary effect and reserves dropped again to some critical threshold in mid-1996, leading to the start of the crisis. During 1997, after several devaluations superior to $50 \%$, the exchange rate of the Bulgarian Lev (BGL) with respect to the US Dollar (USD) suffered an impressive devaluation of $230 \%$, reserves felt to a historical minimum of 300 million USD, monthly inflation and the base interest rate rose up to $250 \%$, real activity shrank by $7 \%$ and unemployment climbed to $14 \%$ (for more details see Berlemann and Nenovsky, 2004).

Following this severe twin (currency and banking) crisis, there was need for a new monetary system. This new system should answer to two requirements: stop the crisis and provide long-term stability. Since an inflation-targeting system is based on reputation and thus powerless in the short-run, Bulgaria adopted on February the $17^{\text {th }} 1997$ the decision to introduce a Currency Board (CB) monetary system (the CB became effective after the April elections, namely starting July the $1^{\text {st }}$ 1997). Thus, Bulgaria joined Estonia and Lithuania who introduced CBs in 1992 and 1994 respectively. ${ }^{1}$

The goal of the present paper is to explore the influence of the adoption of the CB monetary system in terms of the integration of Bulgaria into the European Monetary Union (EMU). Indeed, embracing a $\mathrm{CB}$ is a rather strong and radical decision, since monetary authorities lose the autonomy of the monetary policy, as "market forces alone determine the quantity of notes and coins in circulation" (Schuler, 1992, p.2). Thus, it would be interesting to examine if the cost of accepting the loss of monetary policy autonomy was backed up by better performances, particularly with respect to other Central and Eastern European Countries (CEEC) that conserved monetary autonomy, in terms of EMU integration.

\footnotetext{
${ }^{1}$ Although currently relatively few countries still use CBs (among which, Bosnia, Djibouti or Hong Kong), they continued to be studied as they may provide insights about related forms of monetary arrangements (i.e. dollarization or monetary unions).
} 
To this end, we move away from the existing literature by exploring the consequences of the presence of a $\mathrm{CB}$ in two directions. First, we aim at identifying an appropriate exogenous monetary shock, as domestic monetary variables, and in particular the Bulgarian interest rate, which are often used as a source of monetary disturbances (see, for example, Elbourne and de Haan, 2006) are endogenous in a CB monetary system. ${ }^{2}$ After considering several potential candidates, we select the ECB interest rate and the FED interest rate as the main sources of monetary shocks affecting the Bulgarian economy. ${ }^{3}$ Second, as recently stressed out by Egert and MacDonald (2009), the largest majority of papers studying monetary policy transmission build on (recursive) Structural VARs (SVARs). However, while more is known about monetary policy transmission in countries with autonomous monetary policy, the evidence about the order in which shocks propagate under a $\mathrm{CB}$ is still very crude. To avoid this kind of misspecifications, we use a different approach, based on Generalized Impulse Response Functions (GIRFs) developed by Pesaran and Shin (1998), which, contrary to (recursive) SVARs, present the property of being insensitive to the ordering of variables. ${ }^{4}$

We find first that the responses of Bulgarian variables to ECB shocks are short-lived and little significant, contrary to what is usually found in the literature for other CEEC with monetary autonomy (see the survey of Egert and MacDonald, 2009). ${ }^{5}$ Second, we question the robustness of our findings by accounting for the three main sources of cross-country heterogeneity outlined in the literature (see Elbourne and de Haan, 2004), namely i) different identification schemes, ii) different variables, and iii) different time periods. Finally, we compare the responses of Bulgarian variables to ECB and FED interest rate changes respectively, and find that ECB shocks are more rapidly absorbed and present lower significance. Based on theses findings, Bulgaria seems to be better integrated than other Central and Eastern European Countries (CEEC), and the adoption of a CB monetary system seems to have contributed to this process.

\footnotetext{
${ }^{2}$ We use the term "exogenous" to account for a discretionary decision: for example, the ECB interest rate is exogenous, as it may be discretionary changed by the $\mathrm{ECB}$, while variations in the Bulgarian interest rate are endogenous, in the way that, because of the presence of a $\mathrm{CB}$, they are determined exclusively by market responses and not by the Bulgarian National Bank (BNB).

${ }^{3}$ The Bulgarian LEV is currently anchored to the EURO (1 EUR $=1.95583$ BGL) through the CB mechanism. Section two develops the way the FED interest rate may affect the Bulgarian economy.

${ }^{4}$ To put it differently, the use of GIRF prevents us from imposing constraints about which we have little knowledge (however, for robustness issues, we propose a comparison of our results with those from a SVAR).

${ }^{5}$ The few studies dealing with monetary policy transmission in countries with monetary systems close to Bulgaria (see, for example, Lättemäe, 2003, for Estonia; Vetlov, 2003, for Lithuania; or Babich, 2001, for Latvia) also emphasize modest responses.
} 
The rest of the paper is organized as follows. In section two we discuss the choice of an exogenous monetary shock, and then describe the data and the model. Section three reports our main results and several robustness tests, and section four concludes.

\section{The sources of monetary volatility in a CB and data presentation}

\subsection{The identification of exogenous monetary shocks}

The architecture of the Bulgarian CB monetary system involves the existence of a fixed exchange rate between the BGL and the anchor (the EURO). An important feature is that under this monetary arrangement neither monetary aggregates, nor the domestic interest rate, can be considered as pure monetary domestic instruments and used accordingly. In terms of our future modelling, this implies that studying exogenous changes in either domestic interest rate or monetary aggregates (which is econometrically computable) has limited interpretation (see, for example, Hanke and Schuler, 1994). Thus, to explore the relative integration of the Bulgaria economy in the EMU, we study the responses of the Bulgarian economy to two external monetary shocks.

First, and most important, we focus on changes in the ECB interest rate. Since the Bulgarian currency is fixed against the EURO, changes in the ECB interest rate should exert a considerable effect on the Bulgarian domestic interest rate and further on all key macroeconomic variables.

Second, notice that pegging against an anchor does not completely offset fluctuations, since the domestic currency can float against other trade partners' currencies. An interesting example is Lithuania, where from 2002 on the currency was anchored to the EURO, while an important share of trade is done with Russia (although the EU is the most important trade partner). In this case, studying the effect of changes in the monetary conditions (i.e. the interest rate) that affect the currency of an important trade partner (different from the "anchor currency" partner) might produce interesting insights. Consequently, we look at the reaction of the Bulgarian economy following variations in the FED interest rate. ${ }^{67}$

\footnotetext{
${ }^{6}$ The effect of changes in the FED interest rate transits through the trade activity with the United States, but also (particularly) with countries that are/were linked to the USD in recent times, namely Turkey, Russia, etc.

${ }^{7}$ A certain strand of the literature focuses on the distinction between "first generation" (orthodox) and "second generation" (quasi-CB) Currency Boards (see Hanke, 2007). Since the Bulgarian CB is of second-generation, the BNB may, contrary to orthodox CBs, run some restricted form of active monetary policy, mainly through three instruments: the minimum required ratio (see Nenovsky et al, 2001), the BNB account with the Government (see Nenovsky and Hristov, 2002), and the Lender-of-Last-Resort (LOLR) function (see Berlemann and Nenovsky, 2004). However, as pointed out by these authors, changes in these instruments are extremely rare and their
} 


\subsection{Data and methodological considerations}

To investigate the effects of monetary policy disturbances on the Bulgarian economy, we consider a multivariate representation. We first describe the data and examine the time series properties of variables, before discussing the modelling strategy.

\subsubsection{Data set and unit root tests}

Data are quarterly and cover the period Q3:1999 until Q4:2010, leading to 46 observations. Even if Bulgaria introduced the CB on July the $1^{\text {st }} 1997$, our sample starts with the $3^{\text {rd }}$ quarter of 1999 , to allow for variables to "stabilize" after this important shock. ${ }^{8}$ As detailed above, since changes in Bulgarian monetary variables are not discretionary-decided, we turn first our attention to the ECB refinancing interest rate. However, changes in the ECB interest rate are too rare to produce the necessary amount of variability in our analysis, and, in line with other studies (see, for example, Reynard, 2007), we use the LIBOR EUR 3 months interest rate $\left(i^{E U}\right)$.

In the basic model, we study the impact of the $i^{E U}$ on four variables, which we select with respect to two goals. On the one hand, we aim studying the response of most important monetary (since little is known about their behaviour in a CB monetary system) and real variables. On the other hand, we restrict our benchmark VAR to five variables, since results may be already affected by the size of the sample.

The four remaining variables in our basic VAR are the following. First, we consider the Bulgarian interest rate $i^{B G}$, defined as the "money market rate" (three months maturity). Indeed, because of the $\mathrm{CB}$, the $\mathrm{BNB}$ has no interference on this interest rate and $i^{B G}$ may be considered to properly characterize the credit market stance. Second, we focus on a broad money indicator $M$, defined as the annual quarter-to-quarter growth rate of nominal $M 3$. To capture the effects on prices, we use the annual (quarter-to-quarter) growth rate of consumer prices (inflation) $I P C .{ }^{9}$ Finally, to look for some real economy effects, we include the annual (quarter-to-quarter) growth rate of real output (GDP), denoted by $Y$. All these variables, as well as the LIBOR EUR 3 months interest rate, come from the BNB dataset.

impact on the Bulgarian economy is significantly smaller with respect to the effect of the ECB and the FED interest rates.

${ }^{8}$ For example, changes in consumer prices (inflation) greatly oscillate among high values $(65.7 \%$ change in Q1:1998 relative to Q1:1997) and negative values (-0.9\% change in Q2:1999 relative to Q2:1998).

${ }^{9}$ Lavrac (2004) discusses the inflation targeting in the Czech Republic, Hungary and Poland, and concludes that the appropriate measure for inflation is the "headline inflation rate" (the change in consumer price index and not inflation net of regulated prices). See also Orlowski (2000) and Coricelli, Egert and MacDonald (2006). 
The first step of the analysis is to look at the macroeconomic data univariate properties. Two classes of tests allow investigating the presence of a unit root: unit root tests (see $\mathrm{Ng}$ and Perron, 2001) and stationarity tests (the most popular are the KwiatkovskiPhillips-Schmidt-Shin KPSS, 1992, and the Leyborne-McCabe LMC, 1999). ${ }^{10}$ As recently stressed by Carrion-i-Silvestre and Sanso (2006), the main drawback of stationarity tests is the difficulty entailed by the estimation of the long-run variance needed to compute them. We follow their recommendations and apply the KPSS test using the procedure developed by SulPhillips-Choi (SPC, 2005) to estimate the long-run variance. This strategy involves less size distortion compared to the LMC test, while preserving reasonable power.

The results of the KPSS tests, reported in Table 1, indicate that the null stationarity hypothesis around a constant or around a linear trend root cannot be rejected at the 5\% level of significance, for all macroeconomic series under consideration (the first five appear in the first model and the next two in the second one). Therefore, it seems reasonable to treat all series under consideration as $I(0)$ processes. ${ }^{11}$

Table 1 - Stationarity tests for macroeconomic series ${ }^{(a)}$

\begin{tabular}{lcc}
\hline \hline Series & KPSS with constant & KPSS with time trend $^{(\mathrm{b})}$ \\
\hline \hline ECB Interest Rate (IEU) & 0.223756 & 0.082383 \\
Money Market Rate (IBG) & 0.093478 & 0.085510 \\
Money BG (M) & 0.245731 & 0.115434 \\
Inflation BG (IPC) & 0.096264 & 0.085243 \\
Output BG (Y) & 0.272918 & 0.134829 \\
\hline FED Interest rate (IUS) & 0.224372 & 0.105196 \\
BGL/USD Exchange rate (BGL) & 0.170843 & 0.142673 \\
\hline \hline & Critical Values & Critical Values \\
cv (1\%) & 0.739 & 0.216 \\
cv (5\%) & 0.463 & 0.146 \\
cv (10\%) & 0.347 & 0.119 \\
\hline \hline
\end{tabular}

(a) We apply the KPSS test using the procedure of Sul et al. (2005) to estimate the long-run variance. (b) We used the AIC criterion to select the order of the autoregressive correction with pmax $=\operatorname{int}\left[12(T / 100)^{1 / 4}\right]$. We report the finite sample critical values drawn from the response surfaces in Sephton (1995). The null hypothesis of the KPSS test is "stationarity around a constant or around a (linear) time trend".

\subsubsection{Methodological Considerations}

Since all series taken in level are integrated of order zero, it is possible to investigate the dynamic relationships among our set of variables in a VAR model using innovation accounting methods such as impulse response functions. For the reasons described in the introduction we implement the recently developed "generalized" impulse response functions

\footnotetext{
${ }^{10}$ In contrast to unit root tests, stationarity tests specify the null hypothesis of stationarity against the alternative of non-stationarity, so they can be seen as the reversal complement of the unit root tests.

${ }^{11}$ Besides, on the one hand, further unit root tests (for example Elliott-Rothemberg-Stock ERS, 1996, results are available upon request) reject the presence of a unit root in all considered series. On the other hand, since in all considered VARs in levels IRFs rapidly come to zero after a shock on a variable supports that series are $I(0)$.
} 
(GIRFs) suggested by Pesaran and Shin (1998), which are insensitive to the ordering of the variables in the VAR (see Appendix A). ${ }^{12}$ Besides, the ability of the GIRFs to capture immediate responses of endogenous variables to shocks is clearly useful when information is quickly assimilated, as it may be the case in a CB.

\section{VAR investigation and examination of dynamic responses}

In the first subsection we study the response of variables following an impulse on the ECB interest rate. These results are completed in the second subsection by evidence following a change in the FED monetary policy.

\subsection{The effect of a change in the ECB interest rate on the Bulgarian economy}

We first illustrate results for the basic VAR, before exploring the robustness of our findings.

\subsubsection{The basic model}

Since our results are based on GIRFs, the order of variables in the VAR is unimportant. Let us suppose, without generality loss, the following transmission scheme: $i^{E U} \rightarrow i^{B G} \rightarrow Y \rightarrow I P C \rightarrow M$. An ECB interest rate $\left(i^{E U}\right)$ shock is considered to impact first the Bulgarian interest rate $\left(i^{B G}\right)$. Changes in interest rate $i^{B G}$ are supposed to affect the growth rate of real activity (output), followed by changes in consumer prices IPC and in domestic nominal money growth $M .^{13}$

Before implementing a generalized impulse response analysis, we must choose the optimal lag length in the benchmark VAR. Using the LR test and four information criteria (see Appendix 1), we choose the lag 1. Appendix 2 reports the inverse roots of the AR characteristic polynomial of the estimated VAR and clearly confirms its stationarity, since all roots lie inside the unit circle (see Lütkepohl, 1991). Consequently, the estimated VAR may be used for a generalized impulse response analysis. ${ }^{14}$ To check the quality of the multivariate estimation, we performed several test concerning the serial correlation (LM tests), as well as ARCH tests and the Jarque-Bera normality test. Results in Appendix 1 confirm that the VAR model is well behaved and not subject to misspecification, since all usual hypotheses

\footnotetext{
${ }^{12}$ For robustness issues, we compare GIRFs with IRFs from a SVAR (see section 3.1.2 below).

${ }^{13}$ According to KPSS stationarity tests in Table 1, all series are considered in level and we include a constant.

${ }^{14}$ Since (i) all series of our database are integrated of order zero and (ii) the inverse roots of the characteristic AR polynomial of the estimated VAR all lie inside the unit circle, the question of cointegration testing between these series is of course not relevant.
} 
concerning the residuals of each equation are verified. Figure 1 below depicts the results of a generalized impulse response analysis for the benchmark VAR, together with their bootstrapped $95 \%$ confidence bands.

Figure 1 - Generalized Impulse Response Functions in the basic model
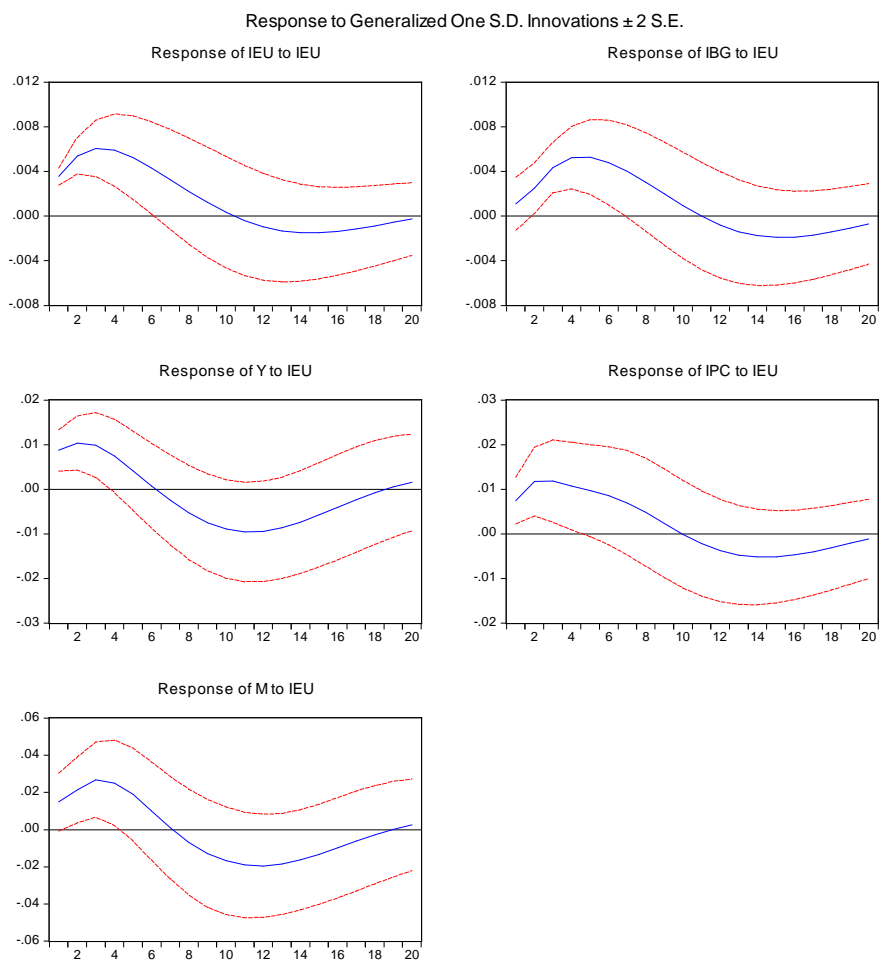

Note for all VARs: The fact that GIRFs to shocks stabilize and come back towards zero indicates on the one hand, that the VAR model is correctly specified and, on the other, that all macroeconomic series are integrated of order zero.

Figure 1 provides interesting evidence about the reaction of domestic variables in a CB monetary system, following exogenous external shocks. First, we observe that an increase in the ECB interest rate leads to a non significant increase in the Bulgarian interest rate on the impact; afterwards, the Bulgarian interest rate follows the ECB rate with a small lag (about 12 quarters). However, the response of the Bulgarian interest rate is both short-lasted, since statistically significant at the 5\% lever for only 4 quarters, and with a low magnitude of $0.4 \%$ arising after 4-5 quarters. With respect to the existent literature, two points worth be noticing. First, our result is contrary to previous studies outlining large and persistent effects in CEEC with monetary autonomy. For example, a recent contribution from Gavin and Kemme (2009) finds that the interest rate presents a significant reaction for 12 quarters for Czech Republic, Hungary and Poland. Second, our finding are in line with previous evidence on the existence of small and non-significant responses of the domestic interest rate in countries with monetary systems close to Bulgaria, see EFN (2004) for the CBs in Estonia and Lithuania. Thus, the 
endogenous Bulgarian interest rate is, compared to other countries, intimately linked to the ECB rate, in terms of magnitude, significance and dynamics (lag); this rapid transmission of shocks may suggest that Bulgaria is better integrated with the EMU with respect to other CEEC (as it also seems to be the case for other countries with a CB monetary system).

What is however striking is that output first increases, before exhibiting the traditional hump-shaped, as a response to a higher interest rate. As for the adjustment of the Bulgarian interest rate, this may be seen as a sign for good monetary integration. Indeed, agents anticipate that, given the strict monetary linkage of Bulgaria with the EMU through the $\mathrm{CB}$, the divergences between the Bulgarian interest rate and the ECB rate cannot be long-lasting; or, to put it differently, the Bulgarian interest rate is expected to closely follow the path of the ECB rate. However, for a short period of time the domestic interest rate is lower with respect to the ECB rate, which may enhance investment and consumption, provided that the financial market is sufficiently integrated to the Euro Area markets in order to supply the necessary amount of liquidity; ${ }^{15}$ in this case, output increases. Nevertheless, as explained above, the interest rate differential is short-lived: as soon as the two rates are converging, the Bulgarian output exhibits the traditional hump-shaped response according to the related literature; yet again, this response is statistically non-significant. ${ }^{16}$

Consequently, the behaviour of the Bulgarian output presents two different outcomes with respect to other CEEC: on the one hand, there is no evidence of such a positive reaction of output in the short-run (see Table 5 in Egert and MacDonald, 2009, surveying results for CEEC in comparable econometric frameworks). On the other hand, this positive short-run effect moves the entire path of the output upwards, making the medium-run effects nonsignificant. Our findings contradict recent evidence for CEEC with monetary autonomy, outlining significant and persistent output contractions (see Borys, Horvath and Franta, 2009, for the Czech Republic, and Touré, Trabelsi and Dufourt, 2009, for Hungary and Poland).

Concerning the remaining variables, money positively responds in the short-run, which may be in accordance with the $\mathrm{CB}$ functioning: since the money stock in Bulgaria is money-demand determined, the raise in nominal M3 naturally follows the short-run increase in output (a transaction motive). As for prices, in a country with complete autonomy of

\footnotetext{
${ }^{15}$ We elaborate on the Bulgarian financial sector in the next section (see the robustness tests (b)).

${ }^{16}$ There exists an alternative explanation for the positive reaction of output following a monetary contraction, equally based on the crucial role of expectations. Using monthly data, Elbourne and de Haan (2006) report such an effect for Romania, which in their view may arise if the increase in the interest rate is seen as a change in the monetary strategy for fighting inflation, in high inflation countries. This explanation may also apply to Bulgaria, where the fixed exchange rate strictly constraints the Bulgarian inflation to follow the Euro Area inflation, all the more that in Bulgaria devaluations are forbidden by the law.
} 
monetary policy one would expect an increase in the interest rate to reduce inflation. The counter-intuitive increase in inflation is not new (the so-called "price puzzle", see Sims, 1992), but in our analysis this increase may also reproduce the pressure on prices coming from the increase in output. Finally, notice that the statistical significance of the responses of both prices and money is modest, as it was previously pointed out for other European countries with a CB (see EFN, 2004).

Our interpretation of these results builds on the idea that both Bulgarian interest rate and money are endogenous with respect to external monetary shocks. Since the Bulgarian economy is closely linked to the EMU, both in terms of financial markets and the exchange rate, agents expect the Bulgarian interest rate to rapidly follow the ECB rate dynamics. In our case, agents anticipate a future increase in the domestic interest rate, and, to take benefit of a current interest rate lower than in the future, they increase domestic consumption and investment, which leads to a higher output in the short-run, and moreover higher prices and money. However, as previously acknowledged, these effects are, contrary to evidence for the CEEC with monetary autonomy, short-lived and little significant, suggesting that the Bulgarian economy may be better integrated into the EMU with respect to these countries.

\subsubsection{Robustness Tests}

Before presenting robustness tests, we would like to readdress the issue of comparing GIRFs and SVARs. As already emphasized, the advantage of GIRFs is that responses are immune to the ordering of the variables, which may be important when there is little knowledge about this order (as it may be the case in a CB). However, this also implies giving up the advantages of SVARs, namely the use of economic-derived constraints to achieve SVAR identification. Suppose the transmission mechanisms used above, namely $i^{E U} \rightarrow i^{B G} \rightarrow Y \rightarrow I P C \rightarrow M$, which now reflects our economic intuition. To capture this transmission, we may use a recursive SVAR, with variables specified in this same order. IRFs depicted in Appendix B show that the response of Bulgarian variables is still short-lived and of low magnitude, in line with previous evidence. ${ }^{17}$

With respect to the basic VAR we now consider several experiments to check its robustness, by estimating different alternative VAR models. Elbourne and de Hann (2004) identified three main sources of cross-country heterogeneity, namely i) different identification

\footnotetext{
${ }^{17}$ Finally, one may contest the transmission mechanism described above, in particular after the Bulgarian output. Consequently, we have estimated a SVAR model in which IPC and $M$ change order ( $M$ is placed fourth and $I P C$ fifth). We report that results for this SVAR are qualitatively unchanged (results are available upon request).
} 
schemes, ii) different variables, and iii) different time periods. One could agree that the use of GIRFs protects our results from the first problem. Moreover, if introducing other variables has little impact on our results, ${ }^{18}$ one may criticise our findings with respect to the choice of the time period and the length of the sample (the third problem). To tackle this issue, we discuss three developments of the benchmark VAR: (a) we reduce the number of variables, (b) we consider the option of a structural break with respect to the reforms of the Bulgarian financial system, and (c) we increase the number of observations by using monthly data.

(a) In order to reduce the number of variables in the VAR, the most intuitive transformation is to replace nominal money $M$ and $I P C$ with real money $M R$, in a four-variables $\operatorname{VAR}\left(i^{E U}\right.$, $\left.i^{B G}, Y, M R\right)$. Figure 2 presents the results.

Figure 2 - GIRFs in a four-variables VAR (real money replaces nominal money and inflation) Response to Generalized One S.D. Innovations \pm 2 S.E.
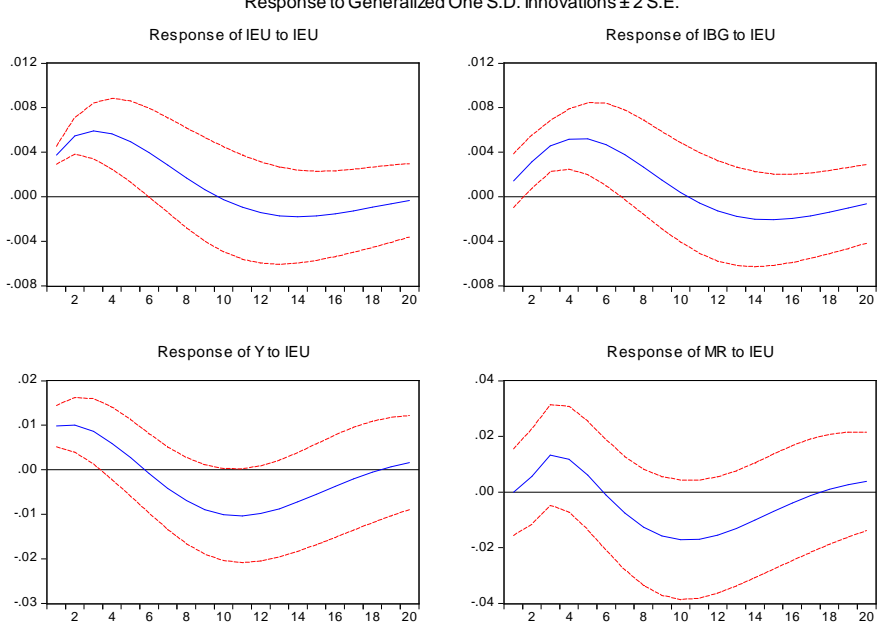

According to Figure 2, following a positive shock on the ECB interest rate, the Bulgarian interest rate path is close to its path in the basic VAR, while output is still significantly raising in the short-run. Real money increases in the short-run, but, contrary to nominal money, its response is not statistically significant, showing once again that in a $\mathrm{CB}$ real effects are narrow.

Appendix 3 supplements the above analysis by depicting reaction functions following a shock on $i^{E U}$ for two more four-variables VARs. First, we explore the response of the Bulgarian interest rate when abstracting from money effects, in the VAR: $i^{E U}, i^{B G}, Y$ and

\footnotetext{
${ }^{18}$ In a previous version of the paper we show that our main results are unaffected when controlling for different variables outside the VAR structure, namely the public deficit (or debt) to GDP ratio, or external prices (or the world commodity prices) to check for the robustness of the initial raise in prices (the usual "price puzzle", although in our setup the rise in prices may be explained by the initial increase in output). These results are unreported here to save space, but are available upon request.
} 
$I P C$. Our results are qualitatively unchanged: the Bulgarian interest rate follows the ECB rate with a lag, while output and inflation significantly increase in the short-run, with all variables displaying short-lived reactions. Second, since the reaction of the Bulgarian interest rate is robust even when abstracting from money, it would be interesting to explore the way money $M$ responds when $i^{B G}$ is absent from the VAR. This strategy could also be supported by the fact that most borrowing is taking place in the anchor currency. As with prior VARs, GIRFs in Appendix 3 clearly support previous conclusions, as reaction functions display comparable shapes and statistical significance.

(b) The second robustness analysis is inspired by Figure 3, which depicts the LIBOR EUR 3 months interest rate $\left(i^{E U}\right)$ and the Bulgarian money market rate $\left(i^{B G}\right)$, both in quarterly data for the 1999:Q3 - 2010:Q4 period.

Figure 3 - The ECB LIBOR EUR 3 months (IEU) and the Bulgarian interest rate (IBG)

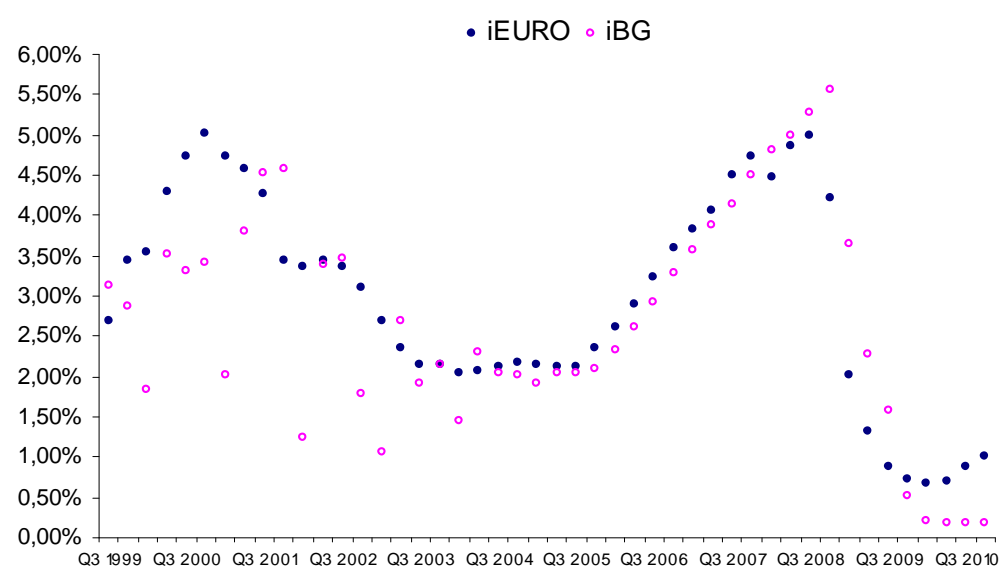

One can easily observe that the LIBOR and the Bulgarian interest rates seem to follow rather different dynamics up until the middle of 2003. Indeed, at that period, the Bulgarian banking system experienced several reforms. These reforms concern the presence of high (above requested) liquidity ratios, the progressive reduction of high risks exposures and of the share of credits to the public sector, and the appearance of a Banking Department within the BNB, which deals exclusively with bank supervision and regulation.

Moreover, the process of bank privatization in Bulgaria was achieved in that period, ${ }^{19}$ and on June the $2^{\text {nd }} 2003$ the BNB adopted the RINGS (Real-time INterbank Gross Settlement) system which allowed for real-time settlement between banks (previously, settlements were allowed at fixed hours, several times a day). Finally, this decision went

\footnotetext{
${ }^{19}$ The number of foreign commercial banks increased from 14 (1997) to 35 (2003), and their share in total banking assets from $32.7 \%$ (1996) to $72.8 \%$ (2005), the largest majority of foreign banks being EMU-based.
} 
along with the suppression of the $0.5 \%$ fee on exchange operations and with the allowance to exchange BGL against EURO brought from abroad (and the other way around).

To account for these changes, we present in Figure 4 the results of the estimation of the benchmark VAR on a sub-sample restricted to start with the observation 2003:Q3. ${ }^{20}$

Figure 4 -GIRFs in the benchmark model estimated on the restricted sub-sample
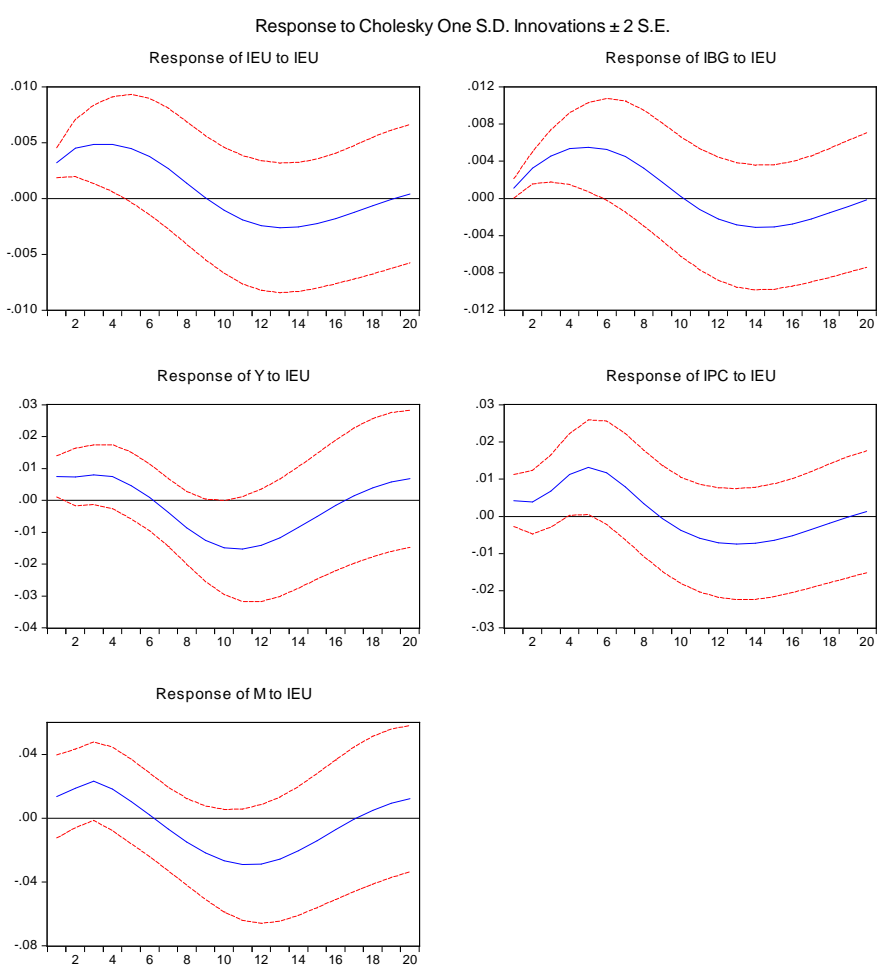

The dynamics of the main Bulgarian variables are remarkably close to the ones from the estimation on the entire sample. The interest rate, output, prices and money exhibit responses in the same direction, however with some minor losses in terms of statistical significance, which may be explained by a relatively important reduction in the number of observations (from 46 to 30 ). Then again, the fact that reaction functions are less significant may add to the fact that, while the $\mathrm{CB}$ may have established the environment for a close integration, the 2003 reforms have contributed to lubricating the mechanism and lead to an even stronger integration between the Bulgaria and the EMU.

(c) our final robustness analysis discusses the fact that, while accounting for the 2003 structural break, results suffer from a reduced number of observations problem. To overcome this issue, we estimate our benchmark model on monthly data, for the sample July 2003 December 2010 (78 observations). Monthly data are available for all considered series except

\footnotetext{
${ }^{20}$ The reduced number of observation in the sub-sample below the breaking point makes results little reliable.
} 
output, which we replace by the industrial production. Figure 5 below depicts response functions following a shock on the ECB interest rate.

Figure 5 - GIRFs in the benchmark model estimated on monthly data Response to Generalized One S.D. Innovations \pm 2 S.E.
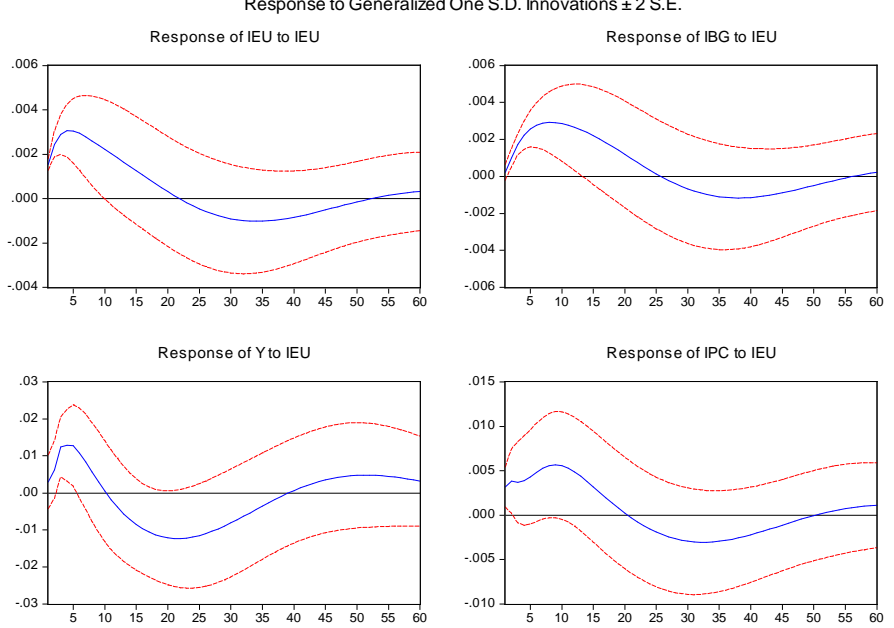

Response of M to IEU

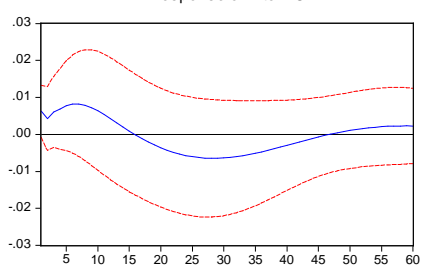

Results on monthly data expand and confirm the findings on quarterly data for the same period (see Figure 4 above). The domestic interest rate follows the ECB rate with a lag in the short-term, and then the two paths exhibit similar dynamics. Output increases in the short run and then becomes rapidly statistically insignificant, as it is the case for prices and money, confirming that in a CB monetary system shocks on the ECB rate are short lasted and of low magnitude. Our results are all the more robust, as some authors have pointed out noticeable changes in the response functions when one changes the frequency of the data (see for example, Egert and MacDonald, 2009).

\subsection{The impact of a change in the FED policy on the Bulgarian economy}

While the analysis up to this point is dedicated to the interest rate channel, we focus in this subsection on the exchange rate channel. Of course, the CB in Bulgaria implies that the exchange rate with the anchor (the EURO) is constant, which is why this analysis is unfeasible. However, Bulgaria still has important trade relations with countries like Turkey, Russia etc., and these countries are/were heavily linked to the USD. Therefore, we estimate that changes in the FED policy, as well as in the BGL/USD exchange rate, may have some influence on the Bulgarian economy. 
We study the reaction of the Bulgarian economy following a change in the FED interest rate, and we assume a transmission mechanism identical to the one in the benchmark model, with two exceptions: we replace the ECB rate with the FED rate, which is now the source of exogenous shocks, and we introduce the Bulgarian Lev to USD exchange rate just after the FED rate. In this way, results are comparable to our previous findings regarding changes in $i^{E U} \cdot{ }^{21}$

Figure 5 - Effects of a change in the FED interest rate
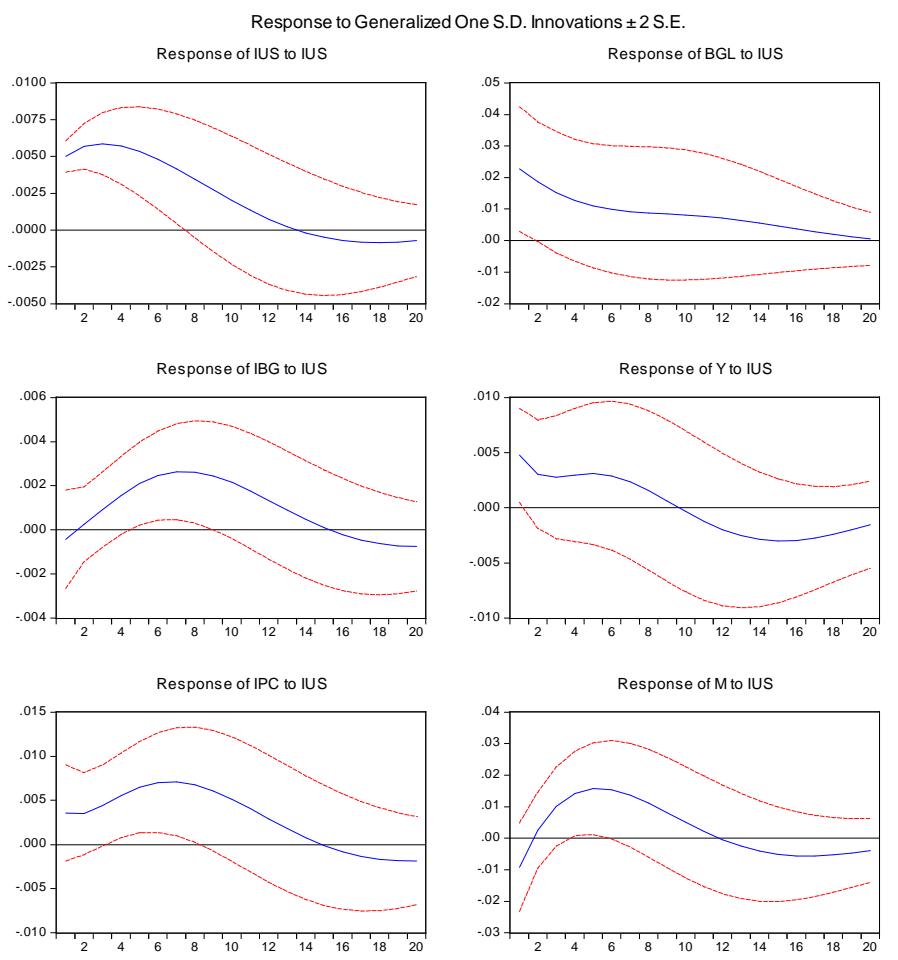

The effects of the FED interest rate on the Bulgarian economy are quite different when compared to the impact of the ECB rate. The Bulgarian interest rate presents no significant reaction in the first quarters, suggesting that shocks on FED take more time to be absorbed. This is also true for prices and money, which exhibit some significance after several quarters. In particular we find again the positive correlation between domestic interest rate, prices and money, as money is basically demand-driven in the CB. Output is statistically significant increasing in the short-run, which may be explained by (i) the initial contraction of $i^{B G}$ which may favour domestic investment, and (ii) by a competitiveness effect that transits through the exchange rate channel. Indeed, observe that an increase in $i^{U S}$ leads to a statistically significant increase in the BGL/USD exchange rate, namely a "standard" depreciation of the LEV with respect to the USD (a higher $i^{U S}$ increases US asset demand relatively to the demand in the rest-of-the-world assets). However, in the medium-run, the Bulgarian interest

\footnotetext{
${ }^{21}$ The FED interest rate is also stationary (see Table 1), while Appendix 4 suggests the adoption of the lag 1.
} 
rate significantly increases and follows the raise in the FED rate, which offsets output. Finally, notice that results are qualitatively unchanged when considering that shocks in the FED transit first through the ECB rate, before affecting Bulgarian variables (see Appendix C).

Consequently, on the one hand, compared to their response to ECB rate shocks, Bulgarian variables respond less in the short-run; the responses become significant latter in time; and they display more persistent reactions to shocks (4 to 5 quarters more for prices and money, for instance). These results may suggest that Bulgaria is more integrated with the EMU, compared to other regions (in our case, the USD area). On the other hand, the exchange rate has relatively little impact (in terms of size, persistence and significance) on the Bulgarian economy, with respect to its impact in countries with autonomous monetary policy, as it is the case for Hungary and Poland where Touré, Trabelsi and Dufourt (2009) conclude to an important role for the exchange rate. ${ }^{22}$

\section{Conclusion}

The goal of the present paper is to present evidence regarding the integration of Bulgaria into the EMU, by analyzing the response of the Bulgarian economy to external monetary shocks. To this end, the presence of a Currency Board monetary system is a crucial issue that one should consider, since under a $\mathrm{CB}$ neither the domestic interest rate, nor the money supply, are the resorts of the Bulgarian National Bank. This raises two problems. On the one hand, one should indentify the possible sources of monetary volatility. Among several possible candidates, we focus in this paper on the ECB interest rate (Bulgarian currency is in a fixed exchange rate with the EURO through the $\mathrm{CB}$ ) and the FED interest rate (countries linked to the USD-area are the second trade partner of Bulgaria, after the EMU countries). On the other hand, the econometric method should account for the fact that there is little knowledge regarding the transmission of external monetary shocks in a CB; for this reason, we replace the commonly used Structural VARs by GIRFs, which are insensitive to the ordering of variables.

We find that the Bulgarian interest rate follows, with a small lag, the ECB interest rate dynamics in the short-run, while it follows the FED interest rate dynamics with a certain delay. Regarding other monetary and real variables (output, money or prices), they exhibit smaller persistence and become non-significant earlier in time following an ECB interest rate

\footnotetext{
${ }^{22}$ The results we emphasize for Bulgaria concern the exchange rate with the USD. Consequently, one should be cautious when comparing them with exchange rate effects in other CEEC, which usually make reference to the exchange rate with the EURO.
} 
shock, compared to a FED interest rate shock. This result could suggest that the CB may have worked as a good convergence device between Bulgaria and the EMU, with respect to other foreign partners.

More important, shocks in the ECB interest rate are found to be short-lived and with little statistical significance, compared to their usually important effects in CEEC outlined by the existing literature. This result holds when accounting for several sources causing the instability of results in the related literature, namely the frequency of observations, the variables considered and the structural breaks, usually regarding changes in the financial market. Consequently, one may assume that Bulgaria is relatively better integrated with the EMU, compared to other CEEC and particularly to countries that conserved monetary autonomy. Further research could deepen our results by investigating the contribution of Bulgarian "second generation" CB features (the required reserve ratio, the Government Account and the LOLR function) in the responses of Bulgarian variables to shocks. 


\section{References}

- Babich, V. (2001) Monetary Transmission in Latvia, Baltic Economic Trends, 2, 16-27

- Berlemann, M., Nenovsky, N. (2004) Lending of First versus Lending of Last Resort: The Bulgarian Financial Crisis of 1996/1997, Comparative Economic Studies, 46, 245-71

- Borys, M., Horvath, R., Franta, M. (2009) The Effects of Monetary Policy in the Czech Republic: An Empirical Study, Empirica, 36, 419-43

- Carrion-i-Silvestre, J., Sanso, A. (2006) A Guide to the Computation of Stationarity Tests, Empirical Economics, 31, 433-48.

- Coricelli, F., Egert, B., MacDonald, R. (2006) Monetary Transmission in Central and Eastern Europe: Gliding on a Wind of Change, Focus on European Economic Integration, 1, 44-87

- EFN (European Forecasting Network) (2004) The Euro Area and the Acceding Countries, Appendix 4, Reports, Spring

- Egert, B., MacDonald, R. (2009) Monetary Transmission Mechanism in Central and Eastern Europe: Surveying the Surveyable. Journal of Economic Surveys, 23, 277-327

- Elbourgne, A., de Haan, J. (2004) Asymmetric Monetary Transmission in EMU: The Robustness of VAR Conclusions and Cecchetti's Legal Family Theory, CESIFO wp. No. 1327

- Elbourne, A., de Haan, J. (2006) Financial Structure and Monetary Policy Transmission in Transition Countries, Journal of Comparative Economics, 34, 1-23

- Elliott, G., Rothemberg, T., Stock, J. (1996) Efficient Tests for an Autoregressive Unit Root, Econometrica, 64, 813-39.

- Gavin, W., Kemme, D. (2009) Using Extraneous Information to Analyze Monetary Policy in Transition Economies, Journal of International Money and Finance, 28, 868-79

- Hanke, S. (2007) Scorecard for Bulgaria's Currency Board, Central Banking, 18, 75-77

- Hanke, S., Schuler, K. (1994) Currency Boards for Developing Countries: A Handbook, ICS Press, San Francisco, California

- Kwiatkowski, D., Phillips, P., Shin Y. (1992) Testing for the Null Hypothesis of Stationarity against the Alternative of a Unit Root, Journal of Econometrics, 54, 159-78

- Lättemäe, R. (2003) EMU Accession Issues in Baltic Countries, Ezoneplus wp. No. 17A

- Lavrac, V. (2004) Fulfillment of Maastricht Convergence Criteria and the Acceding Countries, Ezoneplus wp. No. 21

- Leybourne, S., McCabe, B. (1999) Modified Stationarity Tests with Data-dependent Model Selection Rules, Journal of Business and Economic Statistics, 17, 264-70

- Lütkepohl, H. (1991) Introduction to Multiple Time Series Analysis. Springer-Verlag, Berlin

- Nenovsky, N., Hristov, K. (2002) The New Currency Boards and Discretion: Empirical Evidence from Bulgaria, Economic Systems, 26, 55-72

- Nenovsky, N., Hristov, K., Mihaylov, M. (2001) A Simple Test of Currency Board Automatic Mechanism in Bulgaria, Estonia and Lithuania, Journal des Economistes et des Etudes Humaines, 11, 575-616

- Ng, S., Perron, P. (2001) Lag Length Selection and the Construction of Unit Root Tests with Good Size and Power, Econometrica, 69, 1519-54

- Orlowski, L. (2000) Monetary Policy Regimes and Real Exchange Rates in Central Europe's Transition Economies, Economics Systems, 24, 145-66

- Pesaran, H., Shin, Y. (1998) Generalized Impulse Response Analysis in Linear Multivariate Models, Economics Letters, 58, 17-29

- Reynard, S. (2007) Maintaining Low Inflation: Money, Interest Rates, and Policy Stance, Journal of Monetary Economics, 54, 1441-71

- Schuler, K. (1992) Currency Boards, Dissertation, George Mason University

- Sephton, P. (1995) Response Surface Estimates of the KPSS Stationarity Test, Economics Letters, 47, 255-61

- Sims, C. (1992) Interpreting the Macroeconomic Time Series Facts: The Effects of Monetary Policy, European Economic Review, 36, 975-1000

- Sul, D., Phillips, P., Choi, C. (2005) Prewhitening Bias in HAC Estimation, Oxford Bulletin of Economics and Statistics, 67, 517-46

- Touré, M., Trabelsi, J., Dufourt, F. (2009) Empirical Evaluation of Nominal Convergence in Czech Republic, Poland and Hungary (CPH), Economic Modelling, 26, 293-99

- Vetlov, I. (2003) Monetary Transmission Mechanism in Lithuania, Bank of Lithuania manuscript 


\section{Appendix 1 - Lag selection and other tests for the benchmark VAR model}

LR test (LR, column 1), final prediction error (FPE, column 2), Akaike information criterion (AIC, column 3), Schwarz information criterion (SC, column 4), Hannan-Quinn information criterion (HQ, column 5).

\begin{tabular}{cccccc}
\hline \hline Lag & LR & FPE & AIC & SC & HQ \\
\hline \hline 0 & NA & $1.83 e-17$ & -24.34903 & -24.14216 & -24.27320 \\
$\mathbf{1}$ & $\mathbf{2 1 0 . 9 1 2 7}$ & $\mathbf{1 . 7 4 e - 1 9}$ & $\mathbf{- 2 9 . 0 1 7 2 4}$ & $\mathbf{- 2 7 . 7 7 6 0 4}$ & $\mathbf{- 2 8 . 5 6 2 2 9}$ \\
2 & 28.66443 & $2.39 \mathrm{e}-19$ & -28.75142 & -26.47590 & -27.91735 \\
3 & 28.16468 & $3.06 e-19$ & -28.64420 & -25.33435 & -27.43101 \\
\hline \hline
\end{tabular}

\section{Notes:}

\begin{tabular}{|c|c|c|c|}
\hline Equation & $\mathrm{LM}(4)^{\mathrm{a}}$ & $\mathrm{ARCH}(4)$ & $\mathrm{JB}(2)$ \\
\hline$i^{E U}$ & $1.37994(0.2379)^{\mathrm{b}}$ & $0.12096(0.9741)$ & $3.19091(0.2028)$ \\
$i^{B G}$ & $1.27554(0.2997)$ & $0.15546(0.8565)$ & $2.11424(0.3474)$ \\
$Y$ & $1.12543(0.3543)$ & $0.014404(0.999)$ & $1.11607(0.5723)$ \\
$I P C$ & $1.23807(0.3177)$ & $0.11933(0.9747)$ & $1.17965(0.5544)$ \\
$M$ & $1.780537(0.1005)$ & $1.28388(0.2944)$ & $3.32488(0.1896)$ \\
\hline
\end{tabular}

a - LM (4) denotes Lagrange Multiplicator test of order 4; ARCH (4) denotes Autoregressive Conditional Heteroscedasticity test of order 4; and JB (2) denotes Jarque-Bera (with two degrees of freedom) normality test.

$\mathrm{b}-$ the number in brackets indicates the marginal asymptotic level, namely the probability to exceed the value of the computed statistic. Hence, for instance, a marginal asymptotic level of $23.79 \%(0.2379)$ means that for a significance level smaller than $23.79 \%$, the null hypothesis of absence of residual serial correlation of order 4 cannot be rejected by data. 


\section{Appendix 2 - Inverse Roots of AR Characteristic Polynomial}

Inverse Roots of AR Characteristic Polynomial

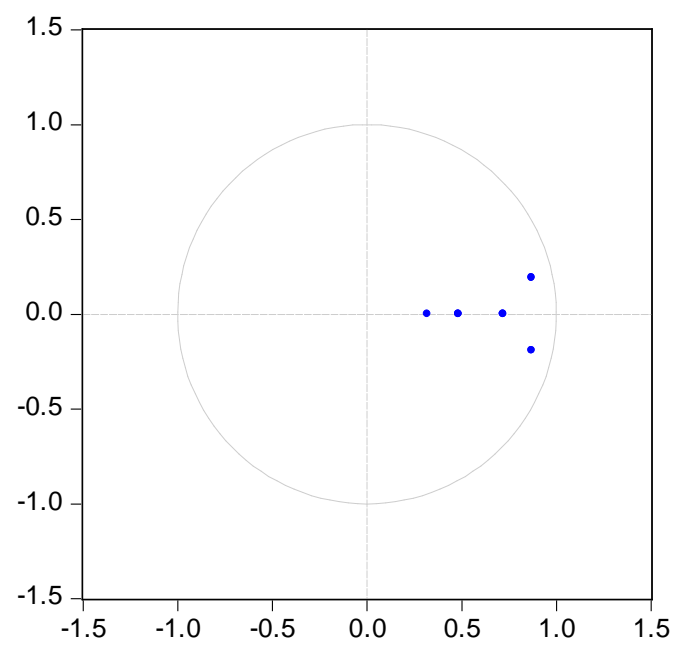

\begin{tabular}{cc}
\hline \hline Root & Modulus \\
\hline \hline $0.869985-0.192693 i$ & 0.891069 \\
$0.869985+0.192693 i$ & 0.891069 \\
0.719316 & 0.719316 \\
0.482733 & 0.482733 \\
0.319098 & 0.319098 \\
\hline \hline
\end{tabular}

Note: no root lies outside the unit circle, thus the VAR satisfies the stationarity condition

\section{Appendix 3 - Reduction of the size of the VAR by restraining the number of variables}

The first four-variables VAR $\left(i^{E U}, i^{B G}, Y, I P C\right)$

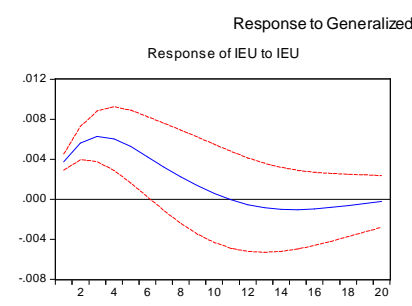

Response of Y to IEU

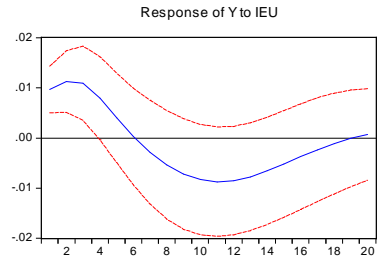

The second four-variables VAR

$$
\left(i^{E U}, Y, I P C, M\right)
$$

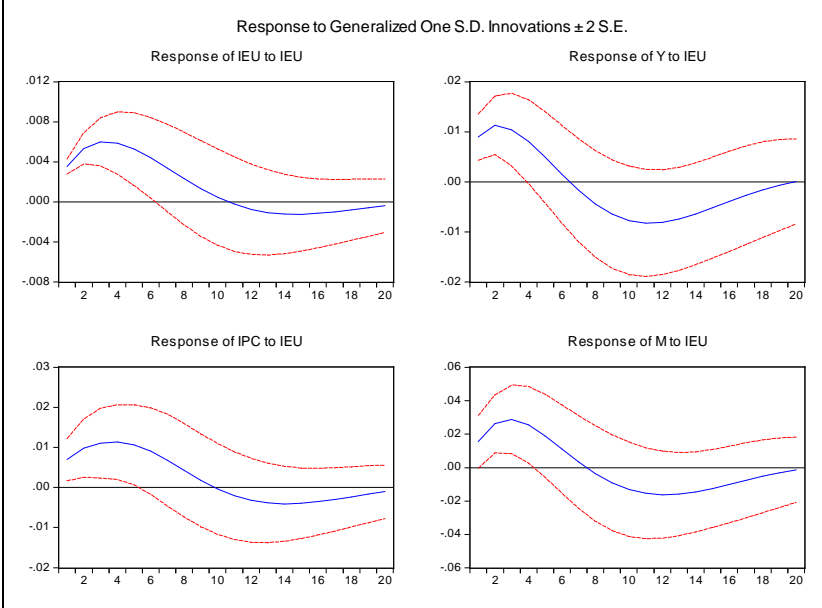

\section{Appendix 4 - Lag selection for the VAR with the FED interest rate and the BGL / USD}

\section{exchange rate}

LR test (LR, column 1), final prediction error (FPE, column 2), Akaike information criterion (AIC, column 3), Schwarz information criterion (SC, column 4), Hannan-Quinn information criterion (HQ, column 5).

\begin{tabular}{cccccc}
\hline \hline Lag & LR & FPE & AIC & SC & HQ \\
\hline \hline 0 & NA & $5.42 e-19$ & -25.03149 & -24.78325 & -24.94050 \\
1 & $\mathbf{2 6 5 . 0 9 8 4}$ & $\mathbf{1 . 5 8 e - 2 1}$ & -30.89144 & -29.15377 & $\mathbf{- 3 0 . 2 5 4 5 2}$ \\
2 & 44.33028 & $2.11 \mathrm{e}-21$ & -30.70579 & -27.47869 & -29.52293 \\
3 & 45.75518 & $2.16 \mathrm{e}-21$ & $\mathbf{- 3 0 . 9 8 0 8 6}$ & -26.26433 & -29.25206 \\
\hline \hline
\end{tabular}




\section{TECHNICAL APPENDICES}

\section{Appendix A - Technical details for the computation of GIRFs}

Suppose that the internal dynamic of the $X_{t}=\left(X_{1 t}, \ldots, X_{n t}\right)^{\prime}$ vector can be suitably captured by the $\operatorname{VAR}(p)$ representation defined as the regression of the $X_{t}$ vector on its past:

$$
B(L) X_{t}=\varepsilon_{t}, t=1, \ldots, T, \text { with }\left\{\begin{array}{l}
E\left(\varepsilon_{t} \varepsilon_{t+s}^{\prime}\right)=\Omega, \text { for } s=0 \\
E\left(\varepsilon_{t} \varepsilon_{t+s}^{\prime}\right)=0, \text { for } s \neq 0
\end{array}\right.
$$

$B(L)=\left(I_{n}-\sum_{i=1}^{n} B_{i} L^{i}\right)$ is a polynomial matrix in $L$ (the lag operator), with $B(0)=I_{n}\left(I_{n}\right.$ the $n$-square unity matrix) and $\varepsilon_{t}=\left(\varepsilon_{1 t}, \ldots, \varepsilon_{n t}\right)^{\prime}$ is a $n$-dimensional vector of white noises (of variance-covariance matrix $\Omega$ ), such as shocks are contemporaneously correlated. The inverse of the roots $(z)$ of the characteristic equation $(\operatorname{Det}[B(z)]=0)$ are supposed to be of modulus strictly inferior to one (stationarity condition), allowing interpreting $\varepsilon_{t}$ as canonical innovations (namely as the part of $X_{t}$ which cannot be linearly explained by its own past).

Using the Wold representation it is possible to rewrite (A1) equivalently under the well-known moving average form:

$$
X_{t}=C(L) \varepsilon_{t}, t=1, \ldots, T
$$

$C(L)=\left(I_{n}-\sum_{t=1}^{m} B_{i} L^{i}\right)$ is a polynomial matrix in $L$, which provides the dynamic effects of each innovation on each variable, with $C(0)=I_{n}$. The GIRF of $X_{i t}$ (for example, the Bulgarian interest rate $i^{B G}$ ) to a unit (one standard deviation) shock in $X_{j t}$ (for example, the ECB interest rate $\left.i^{E U}\right)$ is then given by $\operatorname{GIRF}_{i j, N}=\left(\sigma_{i i}\right)^{-1 / 2}\left(e_{j}^{\prime} \Omega e_{i}\right)$ where $\sigma_{i i}$ is the $i$-th diagonal element of $\Omega, e_{i}$ and $e_{j}$ are selection vectors (with respectively the $i$-th and the $j$ th element equal to one and all other elements equal to zero) and $N$ is the horizon. 


\section{Appendix B - IRFs in the recursive SVAR based on Cholesky decomposition}

Note: Technically speaking, Pesaran and Shin (1998) have shown that for a non-diagonal error variance matrix, the orthogonalized and the GIRFs coincide only in the case of the impulse responses of the shocks to the first equation in the VAR. Since the only shock we study (following our economic analysis in the main text) is the one on the ECB interest rate (the first variable in the VAR), the IRFs in the presented recursive SVAR are identical to the GIRFs in the main text. However, from an economic viewpoint, one should retain that our results are robust in two specifications: in a recursive SVAR with variables placed in an intuitive order and when computing general response functions that are unaltered by the ordering of the variables.

Remark: Under this recursive identification, shocks in $i^{B G}$ (more precisely, responses of $i^{B G}$ to changes in $i^{E U}$ ) contemporaneously affect $i^{B G}, Y, I P C$ and $M$, changes in $Y$ contemporaneously affect $Y, I P C$ and $M$, changes in IPC contemporaneously affect $I P C$ and $M$, while changes in $M$ contemporaneously affect $M 3$ exclusively. Putting $i^{E U}$ first implies that changes in other variables do not contemporaneously affect $i^{E U}$.
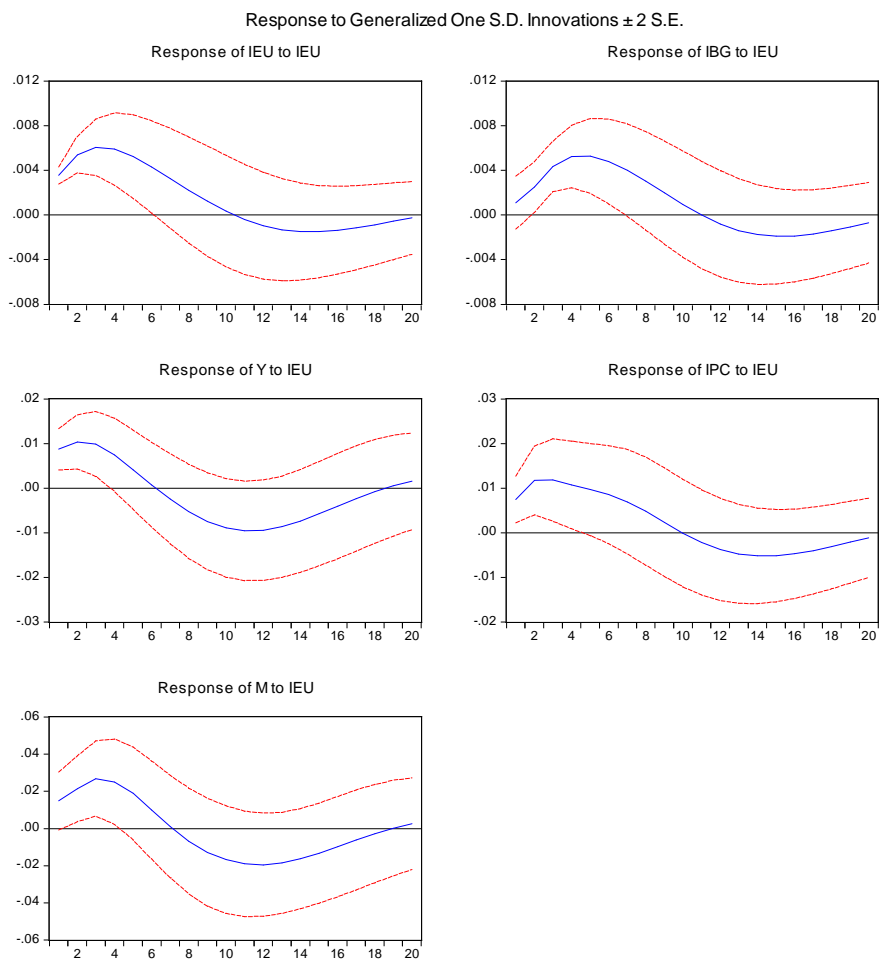

Note: The fact that IRFs to shocks stabilize and come back towards zero indicates, on the one hand, that the SVAR model is correctly specified and, on the other, that all macroeconomic series are integrated of order zero. 
Appendix C - The VAR model with the FED interest rate and the ECB interest rate
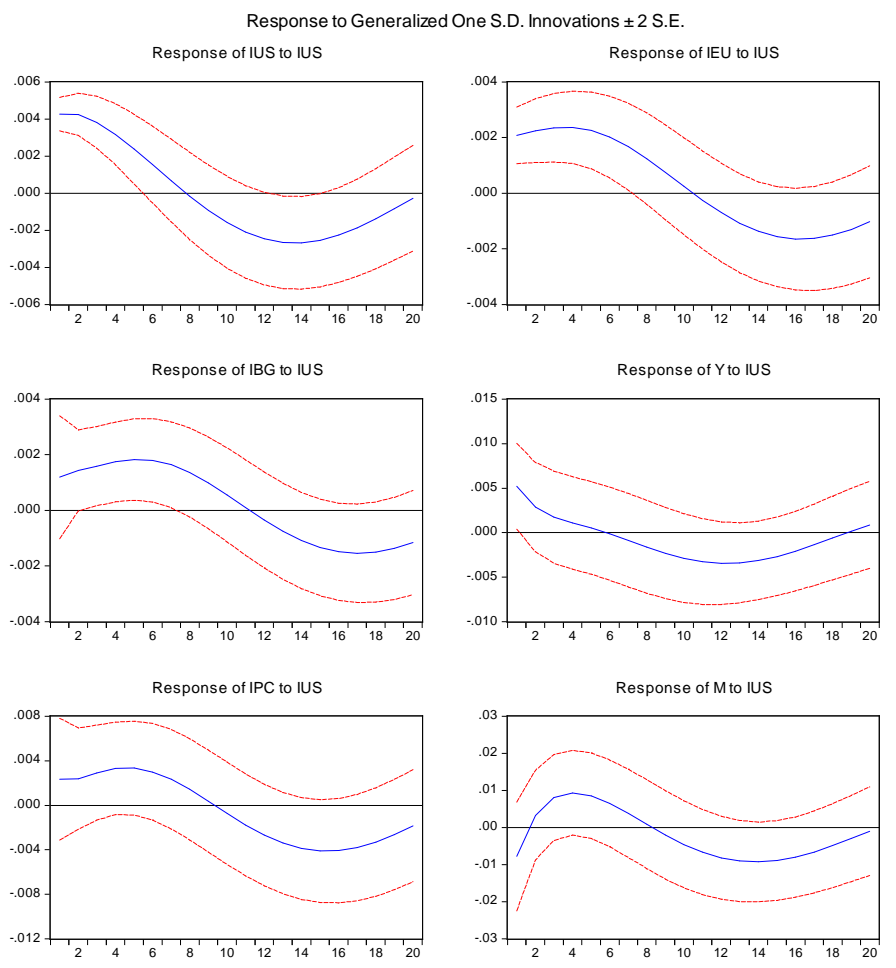